\title{
Ação Popular Como Instrumento Jurídico Para o Exercício do Controle Soberano Democrático: Perspectivas e Desafios
}

\section{Popular Action as a Legal Instrument For The Exercise Of Sovereign Democratic Control: Perspectives and Challenges}

Leandro Gomes da Silva ${ }^{1}$, David Nadler Prata ${ }^{2}$, Vinicius Pinheiro Marques ${ }^{3}$

\section{RESUMO}

A Ação Popular ganhou relevo no cenário político brasileiro com a Constituição de 1934, mas este instrumento não passou de letra morta na legislação em suas primeiras décadas de existência. Tal fato se deu por que o cidadão não era suficientemente informado dos atos sujeitos ao controle popular, situação diferente nos dias atuais em que se pode contar com o auxílio da internet. Por meio do método analítico e da pesquisa bibliográfica, apontou-se que quando da regulamentação pela Lei $4717 / 65$, os meios de publicidade dos atos da administração pública não garantiam um efetivo acesso a informação. Demonstrou-se que na contemporaneidade a internet é essencial no processo de efetivação do direito à informação no Brasil. Concluiu-se que a rede mundial de computadores possibilitou a universalização do acesso à informação tornando qualquer cidadão um potencial fiscal do bem comum, com condições de lutar pelo direito de todos de ter uma Administração Pública proba.

Palavras-chave: Informação. Ação Popular. Internet.

\section{ABSTRACT}

The Popular Action gained prominence in the Brazilian political scenario with the 1934 Constitution, but this instrument was not a dead letter in the legislation in its first decades of existence. This fact was because the citizen was not sufficiently informed of the acts subject to the popular control, a different situation in the current days in which one can rely on the internet. Through the analytical method and the bibliographical research, it was pointed out that when the Law $4717 / 65$ regulates, the means of publicity of acts of public administration do not guarantee an effective access to information. It has been demonstrated that in the present time the internet is essential in the process of realizing the right to information in Brazil. It was concluded that the global computer network made possible the universalization of access to information, making any citizen a fiscal potential of the common good, with conditions to fight for the right of everyone to have a correct Public Administration.

Keywords: Information; Popular Action; Internet.
${ }^{1}$ Mestrando, Mestrado

profissional em Prestação

Jurisdicional e Direitos

Humanos.

E-mail: leandrogs@uft.edu.br

${ }^{2}$ Doutor, Programa de Pós

Graduação em Modelagem

Computacional de Sistemas-UFT.

${ }^{3}$ Doutor, Mestrado profissional

em Prestação Jurisdicional e

Direitos Humanos. 


\section{INTRODUÇAOO}

O principal elemento para o exercício soberano do controle social dos atos da Administração Pública é a informação. Se não houver mecanismos legais cogentes para informar o cidadão, a Ação Popular, mesmo se apresentando como principal instrumento jurídico para o exercício desse controle, não tem efetividade alguma.

$\mathrm{Na}$ seara da propagação da informação, a internet tem sido protagonista. Redes sociais, sites, portais de transparência e tantos outros instrumentos de informação só se tornaram possíveis com o advento da internet. Jamais na história moderna se pôde fiscalizar e defender de forma tão real e efetiva a res publica.

Neste trabalho, pelo método analítico e por meio da pesquisa bibliográfica, pretendese demonstrar como a internet deu condições potenciais de qualquer cidadão ser fiscal do bem comum. Se quando da regulamentação da Ação Popular, por meio da lei 4.717 de 29 de junho de 1965, o cidadão mais engajado precisava vencer uma burocracia enorme para tomar conhecimento dos atos praticados pelos administradores públicos, hodiernamente, até o mais indiferente dos cidadãos, tem ao alcance da mão a possibilidade de monitorálos, muitas vezes involuntariamente, por meio de compartilhamentos de terceiros.

Em prima facie far-se-á uma dissecação histórica da Ação Popular focando nas dificuldades que o cidadão, a época de sua instrumentalização, tinha para exercer seu munus de ser "um fiscal do bem comum" (FERREIRA FILHO, 2008, p. 325) em razão das dificuldades de acesso às informações. Na sequência, demonstrar-se-á como a internet, nos tempos hodiernos, se tornou fundamental para o exercício do direito ao acesso às informações produzidas pelo Estado ou por ele custodiadas.

Por fim, dada a relevância do seu papel na propagação das informações, será discutido como a internet se tornou uma aliada valiosa na universalização do controle democrático, tornando a Ação Popular o instrumento jurídico em potencial com melhor aptidão para esse controle.

2. AÇAOO POPULAR NO BRASIL E O ACESSO A INFORMAÇĀO DA EPOCA DA REGULAMENTAÇÃO

Estar o cidadão suficientemente informado dos atos dos gestores da coisa pública é uma condição essencial para o efeito controle popular. Nesse sentido, a Ação Popular foi por muito tempo considerada letra morta por ausência de instrumentos efetivos que garantissem ao cidadão acesso à informação. 
Como instrumento de controle social da legalidade e lesividade dos atos administrativos, a Ação Popular remonta ao Direito Romano, que garantia ao seu cidadão o direito de defender pessoalmente a res publica (LEITE, 2017). No Brasil, foi na Constituição de 1934 que, embora já tivesse orbitado esse território em Cartas anteriores ${ }^{1}$, a Ação Popular ganhou relevo no cenário político. Contudo, sem uma instrumentalização infraconstitucional, a previsão constitucional não passou de letra morta (CARNEIRO, 2018).

Tentativas de regulamentação tramitaram no congresso ${ }^{2}$, mas o tema que dominava o plenário das casas legislativas nos anos seguintes girava em torno do "estado de guerra" que precedia ao famigerado "Estado Novo". Em meio às tensões geradas pelo executivo cada vez mais sedento por poder, era uma tarefa quase impossível reverberar algo que representasse direitos e garantias fundamentais.

No período de exceção de 1937 a 1945 não houve espaço para Ação Popular no texto constitucional $^{3}$, contudo, retornou a estrutura suprema legal com a Carta Magna de 1946, vindo a ser regulamentada em $1965 \mathrm{com}$ a Lei 4.717 que vigora até a presente data. No aspecto constitucional ganhou maior destaque na atual Carta, promulgada em 1988, que ampliou seu escopo para defender além do patrimônio público e cultural, também o meio ambiente e a moralidade administrativa (artigo 5oㅡ, LXXIII, da Constituição Federal) ${ }^{4}$.

Para o presente trabalho, dar-se-á maior destaque no contexto histórico da regulamentação da Ação Popular e os mecanismos legais da época de acesso às informações. Como reverberado anteriormente, a informação do cidadão é uma premissa sine qua non para o exercício do controle social da probidade administrativa, por esta razão, tanto a tentativa de regulamentação da Ação Popular em 1934, quanto o texto efetivamente aprovado 1965, revelaram que os meios de publicidade dos atos da administração pública

\footnotetext{
${ }^{1}$ Esteve presente na Constituição Imperial de 1824, mas não manteve o status na Constituição de 1881, contudo, continuou aceita até 1916, quando o Código Civil daquele ano, de Clóvis Boviláqua, lhe retira do cenário jurídico ao exigir para propositura interesse econômico ou moral.

${ }^{2}$ Segundo o professor Nelson Carneiro (2018), o deputado Teotônio Monteiro de Barros abriu o debate em torno da regulamentação do inciso constitucional numa luta para que ele não perecesse à mingua de lei; sem espaço para discussão, a Comissão de Constituição e Justiça retornou o projeto ao órgão técnico acompanhado de uma emenda substitutiva do deputado Ferreira de Sá, tendo sido esse último parlamentar o responsável pelo não esquecimento do tema no período ditatorial denominado de Estado Novo (1937 a 1945).

${ }^{3}$ Mas o tema não ficou esquecido. Segundo o professor Nelson Carneiro (2018), o também militante Ferreira de Sá, diante do silêncio do congresso engessado pelo estado de guerra, levou a proposta de regulamentação para apreciação do então Instituto da Ordem dos Advogados do Brasil em conferência realizada em 1937. Com isso, deu-se voz à proposta de modo que mesmo com a instituição do Estado Novo de Getúlio Vagas, o assunto continuou ecoando entre os operadores do direito até que novamente fosse erguida ao status constitucional com Carta de 1946.

${ }^{4}$ Artigo 5 $5^{\circ}$ LXXII da CF/88 - Qualquer cidadão é parte legítima para propor ação popular que vise a anular ato lesivo ao patrimônio público ou de entidade de que o Estado participe, à moralidade administrativa, ao meio ambiente e ao patrimônio histórico e cultural, ficando o autor, salvo comprovada má-fé, isento de custas judiciais e do ônus da sucumbência.
} 
não garantiam o efetivo acesso do cidadão. Muito diferente de hoje que se pode contar com o apoio das ferramentas que se tornaram possíveis com o advento da internet. Hodiernamente cada cidadão tem potencialidade para defender a res publica em qualquer esfera de poder e de qualquer lugar.

$\mathrm{Na}$ primeira proposta legislativa de regulamentar a Ação Popular, consistente no projeto número 2 de 14 de maio de 1936 de autoria do deputado Teotônio Monteiro de Barros (que depois recebeu emenda substitutiva do deputado Ferreira de Sá em sessão do dia 19 de abril de 1937) - (CARNEIRO, 2018) $)^{5}$, ver-se claramente a intenção de instrumentar o acesso à informação. Neste projeto se propôs a obrigatoriedade das repartições em fornecer as "certidões pedidas diretamente pelo interessado na propositura da ação, cobrando apenas a metade dos respectivos emolumentos" ( $\S 3^{\circ}$ do artigo $3^{\circ}$ do referido projeto de Lei). É importante observar que a proposta estabeleceu um direito dever do cidadão, já que ele era obrigado a instruir o processo com a prova do ato ${ }^{6}$.

Denota-se desta proposta legislativa que o cidadão não tinha acesso público a todas as informações que, por natureza, são públicas. Ele deveria/precisaria se reportar ao próprio gestor, cujo ato estava sob investigação, para conseguir ter acesso ao que era necessário para instruir o processo. Ora, seria uma ingenuidade acreditar que o gestor que por ventura estivesse munido de espírito improbo, não seria levado a omitir ou ajustar os documentos e informações solicitadas pelo cidadão para esconder o mal feito. Essa fragilidade do sistema, desestimulava o controle social.

Quando da regulamentação efetiva da Ação Popular por meio da Lei 4.717 de 29 de junho de 1965, o acesso à informação ainda era muito mitigado, não obstante se perceba uma ligeira evolução em relação ao momento do substitutivo de projeto de 1937 . No parágrafo $4^{\circ}$ do artigo $1^{\circ}$ da referida Lei, vigente até a presente data, o cidadão só precisava demandar das entidades administrativas caso julgasse necessário:

$\S 4^{\circ}$ Para instruir a inicial, o cidadão poderá requerer às entidades, a que se refere este artigo, as certidões e informações que julgar necessárias, bastando para isso indicar a finalidade das mesmas.

Percebe-se que o legislador de 1965 considerou que o cidadão já tinha meios suficientes para conseguir provar o ato vergastado e, por isso, podia acionar o judiciário

\footnotetext{
${ }^{5}$ Com a instituição do Estado Novo, a Ação Popular saiu do texto constitucional e a proposta de regulamentação foi arquivada.

${ }^{6}$ Art. $3^{\circ}$ do projeto: À petição inicial juntará o autor uma certidão do ato lesivo ao patrimônio da União do Estado ou do Município ou a fôlha do órgão oficial que o tiver publicado. Dispensar-se-á essa exigência onde não houver jornal oficial ou que publique o expediente do govêrno respectivo, ou se o autor alegar dificuldades opostas pelas repartições ao fornecimento da certidão (sic).
} 
diretamente. Não obstante, ainda assim precisou conferir ao interessado instrumentos ${ }^{7}$ para demandar das entidades o complemento que julgasse necessário. A razão é compreensível: a publicidade dos atos da administração pública como princípio constitucional ainda não era uma realidade na Carta de 1946, de modo que se a referida regulamentação não garantisse acesso a todas as informações dos atos, não se atingiria efetivamente o controle popular pretendido.

Deste modo, tanto a tentativa de regulamentação de 1936 quando a Lei em vigor foram editados em período em que o cidadão não tinha nenhum meio eficiente de informação dos atos da Administração Pública. Era preciso ter muita força de vontade para conseguir instruir um procedimento judicial em defesa do patrimônio público. O cidadão, mesmo aquele mais engajado na fiscalização da probidade administrativa, se deparava com barreiras desestimulantes, mitigando o exercício democrático do controle popular.

Hodiernamente se vive uma realidade muito diferente, não somente pelo fato de se ter uma Constituição que conservou o direito à informação ${ }^{8}$ dentro do rol de "Direitos e Garantias Individuais", como também pelos recursos da internet que a era moderna disponibiliza. Estas duas forças juntas possibilitam um feito inédito: jamais a coisa pública pôde ser de tão perto monitorada e qualquer cidadão teve a possibilidade de exercer o seu direito de ter uma Administração Pública proba e realmente voltada para os interesses coletivos. A internet se tornou essencial no exercício do direito à informação no Brasil, e esse será o próximo tema, de modo a se compreender como a tecnologia se tornou imprescindível para efetividade desse direito fundamental.

\section{A IMPORTÁNCIA DA INTERNET NO EXERCICIO DO DIREITO A INFORMAÇĀO NO BRASIL}

A Lei número 12.527 de 18 de novembro de 2011, batizada de Lei de Acesso à Informação - LAl, representou um marco no Brasil na efetividade do direito constitucional à informação, especialmente no que tange à regulamentação da transparência ativa. Esta Lei regulamentou os incisos XXXIII do artigo $5^{\circ}$, II do $\S 3^{\circ}$ do artigo 37 e o $§ 2^{\circ}$ do artigo 216 da Constituição Federal de 1988 criando mecanismos que possibilitaram a qualquer

\footnotetext{
${ }^{7} \S 5^{\circ}$ do artigo $1^{\circ}$ da Lei $4.717 / 65$ - As certidões e informações, a que se refere o parágrafo anterior, deverão ser fornecidas dentro de 15 (quinze) dias da entrega, sob recibo, dos respectivos requerimentos, e só poderão ser utilizadas para a instrução de ação popular.

${ }^{8}$ Artigo $5^{\circ}$, XXXIII - todos têm direito a receber dos órgãos públicos informações de seu interesse particular, ou de interesse coletivo ou geral, que serão prestadas no prazo da lei, sob pena de responsabilidade, ressalvadas aquelas cujo sigilo seja imprescindível à segurança da sociedade e do Estado;
} 
pessoa, física ou jurídica, sem necessidade de apresentar motivo, o recebimento de informações públicas dos órgãos e entidades ${ }^{9}$. Antes dela, no entanto, outros instrumentos trataram do tema de forma esparsa ${ }^{10}$.

Neste capítulo será demonstrado a importância da internet na efetividade do direito fundamental à informação. Sem uma análise criteriosa se corre o risco de qualifica-la apenas como um dos meios de propagação da informação ao público em geral. Contudo, um aprofundamento no tema será capaz de se compreender que, na verdade, só se pode falar de efetividade do direito à informação a partir das possiblidades emanadas da internet.

No Direito Constitucional brasileiro, o direito à informação esteve inserido no rol de "Direitos e Garantias Fundamentais" nas Cartas de 1934, 1946, 1967 e 1988, contudo, somente vinte e três anos depois da promulgação da Constituição Cidadã ${ }^{11}$ é que se pôde falar em exercício efetivo desse direito.

Na constituição de 1934, batizada de "Segunda República" e primeira a prever o direito à informação dentro do rol de "Direitos e Garantias Fundamentais", ainda que indiretamente, assegurou ao cidadão a comunicação dos despachos proferidos que the interessava, assim como das informações a que estes se refiram. Assegurou ainda o direito de certidões para esclarecimento dos negócios públicos, mas com ressalvas ${ }^{12}$. Esse direito não resistiu à noite longa e sombria do "Estado Novo" sob égide da Constituição de 1937 (CARNEIRO, 2018), contudo, voltou na Constituição de 1946, em repristinação ao texto anterior ${ }^{13}$. Em 1967, ainda que sob o olhar fixo dos militares, a Constituição assegurou a expedição de certidões requeridas às repartições administrativas, para defesa de direitos e esclarecimento de situações ${ }^{14}$.

O ponto em comum que podemos destacar destas previsões constitucionais anteriores à Carta de 1988, é que, com relação ao direito à informação, o Estado não se

\footnotetext{
${ }^{9}$ Acesso à Informação. Governo Federal em: http://www.acessoainformacao.gov.br/assuntos/conheca-seu-direito/a-leide-acesso-a-informacao acessado em 08/06/2018.

10 Leis Complementares: $n^{\circ}$ 131/2009 e no 101/2000 (responsabilidade fiscal); Leis no 10.520/2002 (Pregão Eletrônico), $\mathrm{n}^{\circ}$ 9.784/1999 (Lei do Processo Administrativo), nº 9.507/1997 (Rito processual do habeas data), no 8.159/1991 (Política Nacional de arquivos públicos e privados).

11 Apelido da Constituição de 1988 dado pelo Presidente da Assembleia Nacional Constituinte, deputado Ulysses Guimarães.

${ }^{12}$ Constituição de 1934, artigo 113 item 35 - A lei assegurará o rápido andamento dos processos nas repartições públicas, a comunicação aos interessados dos despachos proferidos, assim como das informações a que estes se refiram, e a expedição das certidões requeridas para a defesa de direitos individuais, ou para esclarecimento dos cidadãos acerca dos negócios públicos, ressalvados, quanto às últimas, os casos em que o interesse público imponha segredo, ou reserva.

${ }^{13}$ Constituição de 1946, artigo 141, § 36 - A lei assegurará: I - o rápido andamento dos processos nas repartições públicas; II - a ciência aos interessados dos despachos e das informações a que eles se refiram; III - a expedição das certidões requeridas para defesa de direito;

IV - a expedição das certidões requeridas para esclarecimento de negócios administrativos, salvo se o interesse público impuser sigilo;

${ }^{14}$ Artigo 150, § 34 da Constituição de 1967.
} 
apresentava como um agente promotor dos direitos e garantias individuais. Do contrário, aparecia de modo inerte, agindo sob demanda, ou seja, a Administração Pública, apenas quando demandada pelo cidadão, Ihe fornecia as informações solicitadas.

Mas o ponto dorsal da discussão é: o Estado tinha condições de exercer uma divulgação proativa ${ }^{15}$ de informações de interesse coletivo e geral; teria ele meios/instrumentos para colocar à disposição da sociedade todas as informações sobre seus atos? Ou a inércia do Estado era proposital, decorrente do pensamento político e ideológico da época?

Não se tem a pretensão de afirmar ou negar que a inércia com relação a esse direito fosse proposital dos constituintes e governos da época, isso demandaria um estudo aprofundando de base sociológica dos fatos historicamente condicionados, contudo, demonstrar-se-á que sem os recursos da internet dos tempos hodiernos, os esforços de uma divulgação proativa de informações de interesse coletivo e geral seriam em vão.

Com efeito, a Constituição de 1988 não inovou textualmente na previsão desse direito fundamental ${ }^{16}$, de modo que a letra fria não garantia uma transparência ativa. Não obstante, quando permitiu que o cidadão participasse ativamente da vida do Estado ${ }^{17}$, interagindo com o governo, propondo projetos de Leis e sugerindo Emendas Constitucionais, abriu caminho para que a regulamentação do direito à informação viesse com essa característica.

Mas a regulamentação desse direito só veio, efetivamente, vinte e três anos depois da promulgação da Constituição de 1988, momento em que a internet se encontrava em franca expansão no Brasil ${ }^{18}$. Como reverberado acima, a verdade é que antes os recursos para dar aplicabilidade a esse direito eram bastantes escassos, ou praticamente nulos. Se assim não fosse, a regulamentação não teria vindo com indicação expressa da importância da internet no processo de informação da sociedade.

\footnotetext{
${ }^{15}$ Entenda-se por divulgação proativa a nominada transparência ativa, que visa promover a interação dos governos com a sociedade, a transparência da gestão e a participação dos cidadãos nos processos da administração pública (SOUSA et al., 2015).

${ }^{16}$ Todos têm direito a receber dos órgãos públicos informações de seu interesse particular, ou de interesse coletivo ou geral, que serão prestadas no prazo da lei, sob pena de responsabilidade, ressalvadas aquelas cujo sigilo seja imprescindível à segurança da sociedade e do Estado (artigo $5^{\circ}, \mathrm{XXXIII} \mathrm{da} \mathrm{CF/88).}$

${ }^{17}$ Parágrafo único do artigo $1^{\circ}$ da $\mathrm{CF} / 88$ - Todo o poder emana do povo, que o exerce por meio de representantes eleitos ou diretamente, nos termos desta Constituição (grifamos); Art. 37, § $3^{\circ}$ da CF/88: A lei disciplinará as formas de participação do usuário na administração pública direta e indireta, regulando especialmente: [...] II - o acesso dos usuários a registros administrativos e a informações sobre atos de governo, observado o disposto no art. $5^{\circ}$, X e XXXIII; Art. 216, $\S 2^{\circ}$ da $\mathrm{CF} / 88$ : Cabem à administração pública, na forma da lei, a gestão da documentação governamental e as providências para franquear sua consulta a quantos dela necessitem.

${ }^{18}$ Segundo as conclusões de Felizola (2011), foi a partir de 2008, com a edição do Decreto 6.424, que alterou o Decreto 4.769/2003, que se estabeleceu no Brasil, inclusive com metas claras, a necessidade de as empresas de telefonia fixa levarem redes de internet a todos os municípios do País.
} 
Pela disposição do artigo $8^{0}$ da LAl que trata da divulgação proativa de informações/transparência ativa, os órgãos e entidades públicas devem promover, independentemente de requerimentos, a divulgação em local de fácil acesso, no âmbito de suas competências, de informações de interesse coletivo ou geral por eles produzidas ou custodiadas. Conforme o parágrafo segundo do referido dispositivo, o meio obrigatório para cumprimento da disposição é a internet:

$\S 2^{\circ}$ Para cumprimento do disposto no caput, os órgãos e entidades públicas deverão utilizar todos os meios e instrumentos legítimos de que dispuserem, sendo obrigatória a divulgação em sítios oficiais da rede mundial de computadores (internet).

Não bastasse a indicação expressa da internet como meio oficial de acesso à informação, a referida Lei ainda estabeleceu requisitos para que isso ocorresse ${ }^{19}$. No decorrer da LAI são feitas outras duas referências à internet como meio oficial e obrigatório de acesso às informações ${ }^{20}$. No seu regulamento (Decreto número 7.724 , de 16 de maio de 2012), são repetidas as disposições legais relativas à obrigatoriedade do uso da internet, especialmente no que concerne à transparência ativa ${ }^{21}$.

Deste modo, constata-se que à luz da LAl, a internet é tratada como meio oficial e imprescindível para a efetividade do direito fundamental à informação, não como uma mera ferramenta, substituível ou até mesmo dispensável.

No mesmo sentido da importância da internet para o efetivo acesso à informação destacado pela LAI, se deu os fundamentos, princípios e objetivos traçados da Lei 12.965 de 23 de abril de 2014, batizada de Marco Civil da Internet no Brasil. Percebe-se que em menos quatro anos, o Legislador cuidou de traçar diretrizes gerais sobre a utilização da internet no espaço nacional, garantido que ela continuasse sua rota de expansão e democratização do seu acesso.

\footnotetext{
${ }^{19} \S 3^{\circ}$ do artigo 8 da LAI - Os sítios de que trata o $\S 2^{\circ}$ deverão, na forma de regulamento, atender, entre outros, aos seguintes requisitos: I - conter ferramenta de pesquisa de conteúdo que permita o acesso à informação de forma objetiva, transparente, clara e em linguagem de fácil compreensão; II - possibilitar a gravação de relatórios em diversos formatos eletrônicos, inclusive abertos e não proprietários, tais como planilhas e texto, de modo a facilitar a análise das informações; III - possibilitar o acesso automatizado por sistemas externos em formatos abertos, estruturados e legíveis por máquina; IV - divulgar em detalhes os formatos utilizados para estruturação da informação; V - garantir a autenticidade e a integridade das informações disponíveis para acesso; VI - manter atualizadas as informações disponíveis para acesso; VII - indicar local e instruções que permitam ao interessado comunicar-se, por via eletrônica ou telefônica, com o órgão ou entidade detentora do sítio; e VIII - adotar as medidas necessárias para garantir a acessibilidade de conteúdo para pessoas com deficiência, nos termos do art. 17 da Lei no 10.098, de 19 de dezembro de 2000, e do art. $9^{\circ}$ da Convenção sobre os Direitos das Pessoas com Deficiência, aprovada pelo Decreto Legislativo no 186, de 9 de julho de 2008.

${ }^{20}$ Artigos 10 e parágrafos, 30 e parágrafos.

${ }^{21}$ Artigo $7^{\circ}$ e seguintes do Decreto número 7.724, de 16 de maio de 2012.
} 
Já no artigo 2ª , inciso II o Legislador estabeleceu como fundamento, dentre outros, que a internet deve ser utilizada na promoção dos "direitos humanos, o desenvolvimento da personalidade e o exercício da cidadania em meios digitais".

O Marco Civil da Internet no Brasil também estabeleceu diretrizes para a atuação da União, dos Estados, do Distrito Federal e dos Municípios no seu desenvolvimento. No rol estabelecido no artigo 24, destaca-se os incisos VI, IX e X:

VI - publicidade e disseminação de dados e informações públicos, de forma aberta e estruturada;

IX - promoção da cultura e da cidadania; e

$X$ - prestação de serviços públicos de atendimento ao cidadão de forma integrada, eficiente, simplificada e por múltiplos canais de acesso, inclusive remotos.

Portanto, concatenando as premissas de que a informação exerce papel fundamental no exercício do direito a uma gestão proba e voltada aos interesses coletivos, e que a internet é imprescindível na efetividade do direito à informação, denota-se que a rede mundial de computadores se tornou um importante instrumento de universalização do controle popular a ser exercido por meio da Ação Popular.

\section{A INTERNET COMO INSTRUMENTO DE UNIVERSALIZAÇAO DO CONTROLE POPULAR}

Tem-se como meta neste tópico demonstrar como a internet deu condições - potencial - para que qualquer cidadão participasse ativamente das decisões do governo, das deliberações legislativas, e, nesse particular, exerça o controle social sobre os atos praticados pela Administração Pública. Tanto o advogado militante na área de defesa dos direitos difusos e coletivos, quanto o cidadão comum, têm condições iguais de defender res publica dos atos ilegais e lesivos ao seu patrimônio.

Não se ignora o fato de que as políticas públicas de acesso à internet no Brasil ainda estão muito aquém do ideal. Felizola (2011, pg. 272) defende que não se vive mais "numa sociedade de completa pobreza digital', não obstante, o referido autor adverte que para termos uma sociedade plenamente conectada:

\footnotetext{
“(...) requer ainda condutas positivas do Estado, que deve oferecer aos cidadãos a possibilidade de se inserirem no contexto de conexão, sob pena de serem privados de diversos outros direitos fundamentais cuja concretizações, no mundo atual, dependem - e dependeram cada vez mais - do acesso a tecnologias da informação" (FELIZOLA, 2011, pg. 272).
}

A advertência de Felizola é muito importante, pois, de fato, a internet com todos os seus recursos ainda constitui um embrião, cujo alcance da evolução foge da compreensão 
humana, de modo que cada vez mais precisar-se-á de políticas inclusivas, estruturantes e capacitativas.

Não obstante, é suficiente para o presente recorte de estudo a constatação de que o Brasil não vive mais numa sociedade de completa pobreza digital. Com efeito, a inclusão digital é sentida de forma notória na contemporaneidade. Pessoas sem qualquer grau de instrução têm possibilidade de acesso às mais variadas formas de redes sociais, aplicativos de mensagens instantâneas, sites jornalísticos etc. Os aplicativos de leitura e transcrição de textos, bem como a possiblidade de enviar e receber mensagens em áudio mesmo, quebraram o paradigma de que saber ler e escrever era requisito para a inclusão digital. Hodiernamente, a participação nas discussões em grupos, seja ela referente à vida privada, política, religião futebol etc. está ao alcance de qualquer pessoa.

No que tange ao acesso às informações públicas, como se viu alhures, a LAI não só garantiu ao cidadão brasileiro a possiblidade de demandar dos órgãos e entidades da Administração Pública o acesso às informações que se tenha interesse, como também obrigou o Estado, por meio da transparência ativa, a promover a divulgação das informações de interesse coletivo ou geral por ele produzidas ou custodiadas (artigo $8^{\circ}$ ). Neste mode, definiu como meio oficial e indispensável a internet (parágrafo $2^{\circ}$ do artigo $8^{\circ}$ ). Na sequência a LAI traçou requisitos mínimos para a divulgação pela internet, conforme parágrafo $3^{\circ}$ do artigo $8^{\circ}$ :

$\S 3^{\circ}$ Os sítios de que trata o $\S 2^{\circ}$ deverão, na forma de regulamento, atender, entre outros, aos seguintes requisitos:

$\mathrm{I}$ - conter ferramenta de pesquisa de conteúdo que permita o acesso à informação de forma objetiva, transparente, clara e em linguagem de fácil compreensão;

II - possibilitar a gravação de relatórios em diversos formatos eletrônicos, inclusive abertos e não proprietários, tais como planilhas e texto, de modo a facilitar a análise das informações;

III - possibilitar o acesso automatizado por sistemas externos em formatos abertos, estruturados e legíveis por máquina;

IV - divulgar em detalhes os formatos utilizados para estruturação da informação;

V - garantir a autenticidade e a integridade das informações disponíveis para acesso:

VI - manter atualizadas as informações disponíveis para acesso;

VII - indicar local e instruções que permitam ao interessado comunicar-se, por via eletrônica ou telefônica, com o órgão ou entidade detentora do sítio; e

VIII - adotar as medidas necessárias para garantir a acessibilidade de conteúdo para pessoas com deficiência, nos termos do art. 17 da Lei no 10.098, de 19 de dezembro de 2000, e do art. 9ํda Convenção sobre os Direitos das Pessoas com Deficiência, aprovada pelo Decreto Legislativo no 186, de 9 de julho de 2008;

Ocorre que ao traçar requisitos mínimos para a transparência ativa pela internet, o legislador acabou por mitigar, pelo menos para o que se propõe a Lei, a falha encontrada 
por Felizola (2011) de baixa qualificação técnica dos usuários no Brasil, o que, segundo aquela autor, seria impeditivo para o gozo pleno dos recursos oferecidos pela internet.

Com efeito, estabeleceu-se que os sistemas governamentais deveriam conter ferramenta de pesquisa de conteúdo que permitam o acesso à informação de forma objetiva, transparente, clara e em linguagem de fácil compreensão, padronizando a forma de divulgação de modo a atingir o maior número de pessoas.

Nos dispositivos retro transcritos, observa-se também que o Estado chamou a sociedade organizada para participação no processo de divulgação das informações por ele produzidas e/ou custodiadas. Ao definir que a gravação de relatórios ocorresse em diversos formatos eletrônicos, com acesso automatizado por sistemas externos em formatos abertos, permitiu que interfaces intermediárias traduzissem os dados mais complexos de modo a possibilitar a compreensão por usuários menos qualificados. Sem propósito de prolixidade, cita-se como exemplos o trabalho realizado pela ONG "Contas Abertas"22, que faz esse trabalho de tradução das informações disponibilizadas, sem prejuízo dos portais de transparência oficiais.

Destaca-se ainda que o compartilhamento de informações pela internet também contribui para o processo de informação do cidadão e, consequentemente, para o exercício do controle popular.

Ocorre que em algumas situações não se estar dispostos a ir além do compartilhamento de uma informação potencialmente ilegal ou lesiva ao patrimônio público. O cidadão se contenta apenas com o apontamento do suposto fato e em expressar a indignação na própria rede, mormente via comentários, produção de memes, piadas e etc. Não obstante, ainda assim, mesmo involuntariamente, este agente social participa do processo de controle popular e zelo pela probidade, pois os compartilhamentos em um determinado momento chegam aos "ouvidos" de um cidadão disposto a agir concretamente, seja via Ação Popular, seja promovendo uma notícia de fato apta a lastrear um inquérito civil.

A crescente onda de fake news no Brasil não pode ser considerada exatamente um problema no que se refere à contribuição dos compartilhamentos de informações para o controle popular, pois a checagem dos fatos é a primeira providência daquele cidadão que pretende intervir, e para isso a própria internet oferece várias ferramentas ${ }^{23}$.

\footnotetext{
$22 \mathrm{http}: / /$ www.contasabertas.com.br/

${ }^{23}$ Um exemplo é uma ferramenta laçado pelo Google em 2017, que possibilita ao usuário buscar por qualquer tema que possa ter relação com uma fake News, e terá como resultado principal um card confirmando ou negando aquela
} 
Deste modo, por meio dos portais oficiais, sites privados, ONG's, redes sociais, aplicativos de mensagens instantâneas, compartilhamentos, etc., hodiernamente a internet possibilita que qualquer cidadão conectado tenha condições de saber o que está se passando na Administração Pública direta e/ou indireta, seja ela Municipal, Estadual ou Federal. A consequência é se tornar um potencial agente de defesa dos interesses coletivos e difusos, em legítimo exercício do controle democrático, sendo a "Ação Popular" o instrumento jurídico próprio para essa postura.

\section{CONSIDERAÇÖES FINAIS}

Para que haja uma efetiva fiscalização dos atos administrativos em geral, o cidadão deve estar suficientemente informado. A Ação Popular se apresentou como um instrumento jurídico importante para que houvesse esse exercício efetivo da soberania democrática, no entanto, o acesso às informações dos atos do governo e entidades da Administração Pública, como regra, não era uma realidade presente no período em que ela foi regulamentada. Deste modo, naquele período histórico o controle popular a ser exercido pelo cidadão ficou prejudicado.

O direito ao acesso à informação no Brasil, por sua vez, como direito e princípio fundamental, remonta às constituições de 1934, 1946, 1967 e 1988, contudo, somente vinte e três anos depois da promulgação da última Constituição, com a regulamentação por meio da Lei de Acesso à Informação - LAI (Lei número 12.527 de 18 de novembro de 2011), é que se pôde falar em exercício efetivo desse direito. A transparência ativa também ganhou força com a regulamentação do direito à informação, possibilitando a interação dos governos com a sociedade, a transparência da gestão e a participação dos cidadãos nos processos da administração pública.

Não foi uma coincidência que a regulamentação ocorreu exatamente no momento em que a internet se encontrava em franca expansão no Brasil. A rede mundial de computadores se tornou o meio oficial e obrigatório dos órgãos e entidades públicas promoverem, independentemente de requerimentos, a divulgação em local de fácil acesso, no âmbito de suas competências, de informações de interesse coletivo ou geral por eles produzidas ou custodiadas. Também nesse, o marco civil da internet cuidou de traçar as diretrizes necessárias para garantir sua expansão livre e democrática.

informação. Mas informações em https://canaltech.com.br/mercado/contra-fake-news-google-traz-nova-ferramenta-dechecagem-de-fatos-91894/. Acessado em junho de 2018. 
O Brasil não vive mais uma condição de pobreza digital. A inclusão digital é sentida por todos, mesmo que timidamente. Qualquer pessoa, ainda que sem qualquer grau instrução, tem acesso às mais variadas formas de redes sociais, aplicativos de mensagens instantâneas, sites jornalísticos etc. Essa qualidade hodierna do brasileiro somada às políticas de acesso à informação trazidas pela LAI, Ihe garantiu condições de acompanhar de modo dirigindo os atos do governo e suas entidades. O compartilhamento de informações pela internet também contribui para o processo de informação do cidadão do modo como está sendo gerida a res publica.

Viu-se, portanto, que o sufrágio universal não é um fim em si mesmo, mas tão somente o começo do longo processo de participação ativa do cidadão na vida do Estado. Hoje no Brasil todo cidadão conectado tem potencial para ser um fiscal do bem comum; tem condições de lutar pelo direito de todos a uma Administração Pública proba; tem na Ação Popular o instrumento jurídico ideal para interferir na defesa dos direitos difusos e coletivos. Jamais na história da república a coisa pública pôde ser de tão perto acompanhada e fiscalizada por qualquer cidadão.

\section{REFERENCIAS}

BRASIL. Constituição da República Federativa de 1988. Disponível em: <http://www.planalto.gov.br/ccivil_03/constituicao/constituicaocompilado.htm>. Acesso em junho 2018.

Constituição Federal de 1967. Disponível em <http://www.planalto.gov.br/ccivil_03/constituicao/constituicao67.htm>. Acessado em junho de 2018.

Constituição Federal de 1946 . Disponível em <http://www.planalto.gov.br/ccivil_03/constituicao/constituicao46.htm>. Acessado em junho de 2018.

Constituição Federal de 1934. Disponível em <http://www.planalto.gov.br/ccivil_03/constituicao/constituicao34.htm>. Acessado em junho de 2018.

Lei no. 4.717 de 29 de junho de 1965. Regula a ação popular. Disponível em: <http://www.planalto.gov.br/ccivil_03/leis/14717.htm>. Acessado em maio de 2018.

Lei $\mathrm{n}^{\circ}$. 12.527 de 18 de novembro de 2011. Regula o acesso a informações previsto no inciso XXXIII do art. 5o, no inciso II do $\S 30$ do art. 37 e no $\S 20$ do art. 216 da Constituição Federal. Disponível em: <http://www.planalto.gov.br/ccivil_03/_ato20112014/2011/lei/l12527.htm>. Acessado em junho de 2018. 
Lei no. 12.965 de 23 de abril de 2014. Estabelece princípios, garantias, direitos e deveres para 0 uso da Internet no Brasil. Disponível em: <http://www.planalto.gov.br/ccivil_03/_ato2011-2014/2014/lei/l12965.htm>. Acessado em março de 2019.

CARNEIRO, Nélson. Das ações populares civis no direito brasileiro. Revista de Direito Administrativo 25/468. Fundação Getúlio Vargas. Disponível em: <http://bibliotecadigital.fgv.br/ojs/index.php/rda/article/view/12141/11061>. Acesso em 09 de maio de 2018.

CASTELLS, Manuel. A Galáxia da Internet: reflexões sobre a Internet, os negócios e a sociedade. Trad. Maria Luiza X. de A. Borges. Rio de Janeiro: Jorge Zahar, 2003. p. 8.

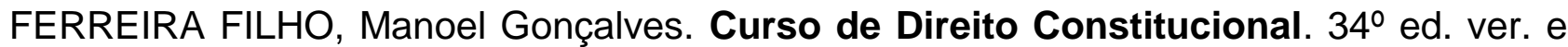
atual. São Paulo: Saraiva, 2008, 326.

FELIZOLA, Pedro Augusto Maia. O direito à comunicação como princípio fundamental: internet e participação no contexto da sociedade em rede e políticas públicas de acesso à internet no Brasil. Revista de Direito, Estado e Telecomunicações, v. 3, n. 1, p. 205-280 (2011).

GAJARDONI, Fernando da Fonseca. Direitos difusos e coletivos I. Teoria geral do processo coletivo. Coleção Saberes do Direito. v. 34. São Paulo: Saraiva, 2012a.

Direitos difusos e coletivos II. Ações coletivas em espécie: ação civil pública, ação popular e mandado de segurança coletivo. Coleção Saberes do Direito.v. 35. São Paulo: Saraiva, 2012b.

ITUASSU, Arthur. e-Representação como comunicação política: Internet e democracia representativa. Famecos (online). 2015.

LEITE, André Henrique Oliveira. Análise das ações populares e ações civis públicas na comarca de Gurupi nos anos de 2013 a 2015. 2017. 113 f. Dissertação (Mestrado em Prestação Jurisdicional e Direitos Humanos) - Universidade Federal do Tocantins, Palmas, Tocantins.

SOUSA, Rossana Guerra; WRIGHT, Gabriel Aragão; PAULO, Edilson; MONTE, Paulo Aguiar. A Janela Que se Abre: Um Estudo Empírico dos Determinantes da Transparência Ativa nos Governos dos Estados Brasileiros. Revista Ambiente Contábil, Universidade Federal do Rio Grande do Norte. 2015, Vol. 7. n. 1, jan./jun. 2015.

SOUZA JUNIOR, Luiz Carlos de. Ação Popular: Um Instrumento Democrático e de Soberania Popular. Revista da Universidade Vale do Rio Verde, Três Corações, v. 14, n. 1, p. 420-428, jan/jun. 2016. 